\title{
A Simulation Study of Weighting Methods to Improve Labour-Force Estimates of Immigrants in Ireland
}

\author{
Nancy Duong Nguyen ${ }^{1}$, Órlaith Burke ${ }^{2}$ and Patrick Murphy ${ }^{3}$
}

As immigration has become a global phenomenon in recent years, a number of European countries, including Ireland, have experienced an influx of immigrants, causing a shift in their national demographics. Therefore, it is important that the EU-LFS yield reliable labour-force estimates not only for the whole population, but also for the immigrant population.

This article uses simulation techniques to compare the effectiveness of four different weighting mechanisms in order to improve the precision of the labour-force estimates from the Irish component of the European Union Labour Force Survey (EU-LFS) called the Quarterly National Household Survey (QNHS). The four weighting methodologies for comparison include the original and the current weighting scheme of the QNHS as well as our two proposed alternative weighting schemes. The simulation results show that by modifying the current QNHS weighting mechanism, we can improve the accuracy of the labour-force estimates of the immigrant population in Ireland without affecting the estimates of the whole population and the Irish nationals.

This article highlights potential issues that other countries with new immigrant populations may face when using the EU-LFS for immigration research, and our recommendations may be useful to researchers and national statistical offices in such countries.

Key words: Quarterly National Household Survey; calibrated weights; poststratification; raking ratio; nonresponse.

\section{Introduction}

During the past two decades, Ireland has experienced large-scale immigration, especially following the enlargement of the European Union (EU) in 2004. Along with the United Kingdom (UK) and Sweden, Ireland was one of only three Old Member States (OMS) that allowed nationals from New Member States (NMS) to access its labour market directly. That resulted in an influx of immigrants from the accession countries to Ireland after 2004. By 2014, approximately twelve per cent of its population were foreign nationals, putting Ireland in sixth place (after Luxembourg, Latvia, Cyprus, Estonia, and Austria) among the

\footnotetext{
1 School of Mathematics and Statistics, University College Dublin, Belfield, Dublin 4, Ireland. Email: duong.nguyen@ucdconnect.ie

2 Nuffield Department of Population Health, University of Oxford, Richard Doll Building, Old Road Campus, Oxford OX3 7LF, United Kingdom. Email: orlaith.burke@ndph.ox.ac.uk

${ }^{3}$ School of Mathematics and Statistics, University College Dublin, Belfield, Dublin 4, Ireland. Email: patrick.murphy@ucd.ie

Acknowledgments: We would like to thank the Irish Social Science Data Archive (www.ucd.ie/issda) and the Irish Central Statistics Office (www.cso.ie) for providing us with the relevant data sets and responding to our enquiries while we work on this paper. This work is supported by the Research Demonstratorship grant from the School of Mathematics and Statistics, University College Dublin.
} 
$28 \mathrm{EU}$ countries for the highest proportion of non-nationals in the population (Central Statistics Office 2015a; Eurostat 2015). Therefore, understanding Ireland's immigrants plays an important role in understanding Ireland's population as a whole.

Of all the national surveys in Ireland, the Quarterly National Household Survey (QNHS), conducted by the Central Statistics Office (CSO), is most widely used for immigration research. The QNHS is the Irish component of the EU Labour Force Survey (LFS) with the primary purpose of producing official statistics on the labour force in Ireland. Considering the significant number of foreign nationals living in Ireland and the growing literature on their assimilation into the Irish society (for example: Barrett and Duffy 2008; O’Connell and McGinnity 2008; Barrett et al. 2011; Kingston et al. 2013), it is important for the QNHS to produce reliable estimates on the labour-market participation of immigrants. This can be achieved by ensuring the representativeness of the QNHS samples not only for the whole population of Ireland, but also for the main nationality groups.

Being a voluntary sample survey, the QNHS suffers from nonresponse and other sampling and nonsampling errors, leading to unrepresentative samples. To account for this, the CSO constructs weights for the QNHS such that weighted samples match population estimates on a number of variables of interest. Since the introduction of the QNHS in 1997, its weighting scheme was modified once in the third quarter (Q3) of 2006 to reflect the change in Ireland's demographics following the EU enlargement. The effectiveness of the pre-Q3-2006 and the current (post-Q3-2006) QNHS weighting schemes for measuring the main characteristics of the immigrant population in Ireland has been examined by Nguyen and Murphy (2015). By comparing the pre-Q3-2006 weighted estimates from the QNHS with the Census 2006 figures and comparing the post-Q3-2006 weighted estimates with the Census 2011, Nguyen and Murphy (2015) come to two conclusions. First, the pre-Q3-2006 weights are not reliable for immigration research. Second, the current weighting scheme performs better than the pre-Q3-2006 scheme with regards to matching the Census figures, but the improvement in performance is minor.

A limitation to the work of Nguyen and Murphy (2015) is its inability to directly compare the efficiency of the pre-Q3-2006 weighting scheme with that of the current scheme. It is not possible to do so in that empirical study because the QNHS data sets do not come with both the pre-Q3-2006 and the post-Q3-2006 weights. Moreover, variables on strata and clusters used in the QNHS design are not available due to data confidentiality rules. Therefore, researchers are unable to calculate their own pre-Q3-2006 and post-Q32006 weights using a real QNHS sample. As a result, one can only compare the efficiency of these two weighting schemes using simulation.

In this article, we re-examine the performance of the pre-Q3-2006 and the current weighting scheme of the QNHS on simulated samples as well as extend the work of Nguyen and Murphy (2015) by proposing two other weighting schemes that can serve as the alternatives to the current QNHS weighting methodology. They are referred to as the modified QNHS and the raking-ratio scheme. We compare the effectiveness of the existing and the proposed QNHS weighting mechanisms for immigration research using simulation exercises.

It should be noted that this is the first time the effects of the QNHS weighting schemes have been examined using simulation and also the first time that alternative weighting 
schemes have been suggested for Ireland's QNHS. Within Europe, there are studies investigating the overall effectiveness of the LFS weighting schemes in Sweden (Hörngren 1992), Finland (Djerf and Väisänen 1993; Djerf 1997), and Norway (Thomsen and Holmøy 1998), as well as their effectiveness specifically for immigration research in Norway (Villund 2010) and in Spain (Martí and Ródenas 2012). These studies are similar to ours in their objectives; however, differences in survey designs and weighting methodologies of the LFS in these countries lead to differences in the methods used in their studies and ours. In general, countries with extensive registers such as Sweden, Finland, and Norway can have more complex weighting methodologies than those without population registers (i.e Ireland). Subsequently, weighting schemes that are proposed for these register countries may not be suitable for other countries.

In summary, the aim of this article is to use simulation to compare the effectiveness of four different weighting methodologies in improving the precision of the labour-force estimates of Ireland's whole population and its main nationality groups. In Ireland, we group the nationalities into five main groups of Irish, UK, OMS, NMS, and Other Nationals. The four weighting schemes are the pre-Q3-2006, the current QNHS, the modified QNHS and the raking-ratio weighting scheme.

We begin with a brief overview of the theory of calibration and a detailed description of the existing and proposed weighting schemes. This is followed by a description of the simulation procedure, corresponding results, and conclusion.

\section{Calibration Techniques}

In survey sampling, calibration refers to the process of reweighting samples such that the final weighted samples are consistent with the population with regards to characteristics of interest. In this section, we will start with the general theory of calibration and its notation, then describe in detail the four weighting methods for comparison.

Suppose that we have a population $U$ of size $N$ and an initial sample $s$ of size $n_{s}$ selected from population $U$ using probability sampling $\left(s \subset U, n_{s} \leq N\right)$. Let $\pi_{k}$ be the probability of selection and $d_{k}$ be the design weight of the $k$ th individual $(k \in s)$ such that $d_{k}=1 / \pi_{k}$. In an ideal world without nonresponse and other sampling and nonsampling errors, the design weight would be the final weight. In reality, this is rarely the case for voluntary sample surveys. Suppose that only $n_{r}$ individuals out of the initial $n_{s}$ selected participants respond to the survey $\left(n_{r} \leq n_{s} \leq N\right)$. Let $r$ denote the sample of $n_{r}$ respondents $(r \subset s \subset U)$.

The aim of calibration is to find the final weights $w_{k}(k \in r)$ that are "as close as possible" to the design weights $d_{k}$ such that the resulting weighted samples match known population estimates for a select number of characteristics (Deville and Särndal 1992). These known population estimates, referred to as auxiliary data, are retrieved from external sources such as the Census, population registers, and other administrative sources. It is well known in survey sampling that proper use of auxiliary information at the estimation stage can reduce bias, improve the precision of variables of interest, and impose consistency with results from other sources (Zhang 2000; Särndal and Lundström 2005; Särndal 2007). In the following subsections, we will discuss two specific calibration techniques called poststratification and raking ratio and their application to the QNHS. 


\subsection{Poststratification}

Poststratification is a classical technique used in survey sampling to adjust for nonresponse bias and improve precision of estimates of variables of interest (Thomsen 1973; Thomsen 1978; Holt and Smith 1979; Jagers 1986). Its concept is similar to that of stratification but strata (referred to as poststrata) are formed after the samples are taken, rather than at the design stage.

Poststratification is a type of calibration approach as it calculates calibrated weights under the constraint that the weighted samples match population estimates broken down by post-strata. These poststrata are formed from the cross tabulation of the auxiliary variables. For example, if we want to poststratify a sample by three age groups and sex, we obtain a cross-tabulated table of six cells. These are the six poststrata, and sex and age are the two auxiliary variables. Poststratification requires a known population count for each of these cells. It then constructs calibrated weights to ensure a perfect match between the sample weighted total and the actual population total for all the cells in the tabulated table. Hence, poststratification is commonly referred to as calibration on known cell counts (Deville and Särndal 1992; Deville et al. 1993).

The poststrata are $H$ disjoint groups such that $U=\cup_{h=1}^{H} U_{h}$ and $r=\cup_{h=1}^{H} r_{h}$. The population size and the sample size of the $h$ th poststratum are $N_{h}$ and $n_{r_{h}}$, respectively. Assume that the population total $N_{h}$ is known for each poststratum $h=\{1,2, \ldots, H\}$. In poststratification, the design weight $d_{k}$ for each $k \in r_{h}$ is adjusted by a factor of $N_{h} /\left(\sum_{k \in r_{h}} d_{k}\right)$, which is the ratio between the true population count and the estimated population count from the sample. The new calibrated weight has the form $w_{k}=d_{k}\left(N_{h} /\left(\sum_{k \in r_{h}} d_{k}\right)\right)$. When these calibrated weights $w_{k}$ are used, the weighted sample will match the population totals for all poststrata.

Poststratification is straightforward to implement and widely used by National Statistical Institutes (NSIs) around the world including the CSO in Ireland.

\subsubsection{The QNHS Pre-Q3-2006 Weighting Scheme}

Between 1997 and Q3 2006, the CSO used simple poststratification to construct its weights based on Age, Sex, and Region. Specifically, the QNHS samples were poststratified by 18 age groups (in five year increments from 0 to 85+ years), sex, and eight NUTS3 regions (Border, Dublin, Midland, Mid-East, Mid-West, South-East, South-West, and West). This resulted in the calibration of 288 poststrata, and the weighted samples matched population estimates for all of these poststrata. In Ireland, population estimates are obtained from the latest Census adjusted for migration and vital statistics (Central Statistics Office 2014).

Within the EU, a number of countries such as Belgium, the Czech Republic, Greece, Cyprus, Luxembourg, Poland, Slovenia, Slovakia, Malta, and Germany currently use poststratification in their calculations of weights for the LFS (Eurostat 2014).

\subsubsection{The Current QNHS Weighting Scheme}

Since Q3 2006, the CSO has constructed weights using two different criteria. The first criterion is exactly that used in the pre-Q3-2006 weighting scheme. In the second criterion, an additional 20 cells are introduced. The QNHS samples are simultaneously poststratified by two age groups (under 15, 15+), sex, and five broad nationality groups (Irish, UK, 


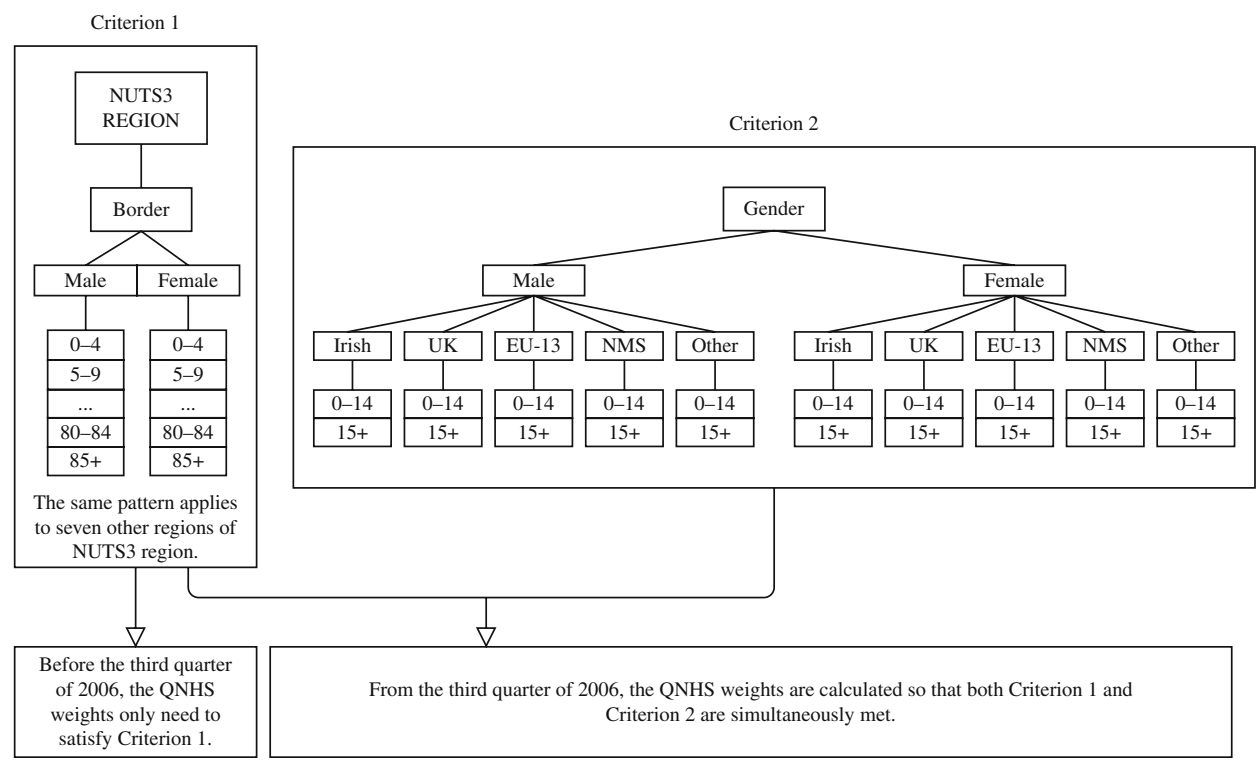

Fig. 1. Diagram of the construction of the QNHS weights (Nguyen and Murphy 2015).

OMS, NMS, and Other). The criteria used in the construction of the pre-Q3-2006 and the current QNHS weights are illustrated in Figure 1. The CALMAR 2 macro in SAS (Sautory 2003) is used to ensure that the current QNHS weights satisfy both criteria simultaneously.

Within the EU, other countries such as Bulgaria, Spain, Italy, Lithuania, the Netherlands, Portugal, Romania, and Macedonia also calibrate their LFS samples using multiple criteria similar to Ireland's current weighting scheme (Eurostat 2014).

\subsubsection{The Modified QNHS Weighting Scheme}

We now propose a modified version of the current QNHS weighting scheme. This new method involves an adjustment to the second criterion while making no change to the first criterion. The second criterion is extended to match population estimates by four age groups (under $15,15-24,25-49,50+$ ). The sex and nationality groups remain unchanged. The weights must now satisfy both of these criteria, that is simultaneous calibrations of 288 cells and 40 cells. As before, this is implemented using the CALMAR 2 macro in SAS. We now introduce another scheme before examining this.

\subsection{Raking Ratio}

While poststratification is a popular calibration technique, there are two scenarios in which it cannot be implemented. The first scenario is when a sample poststratum $r_{h}$ is empty or has an extremely small sample size. The second scenario is when the population count of the poststratum $N_{h}$ is unknown or not reliable. In these situations, survey statisticians may opt for a technique called raking ratio to calibrate their samples.

Formalised originally by Deming and Stephan (1940), raking ratio is a classical method of calculating survey weights when the marginal population count for each auxiliary variable is known, but not the detailed population count for each cell in the cross-tabulated 
table formed by these auxiliary variables. For example, suppose we want to poststratify a sample by three age groups and sex. Assume that we do not know the population counts for all of these six cells; poststratification is therefore not possible. Suppose that from the latest Census, we know the marginal population totals (i.e the number of males and females in the population, the number of people in each of the three age brackets in the population). In this case, we can use the raking ratio method, a reliable alternative technique to poststratification, to calculate the survey weights (Deville et al. 1993). Hence, raking ratio can be referred to as incomplete post-stratification or calibration on known marginal counts (Deville and Särndal 1992; Deville et al. 1993).

Suppose that we want to calibrate a sample using two auxiliary variables with $I$ and $J$ number of levels, resulting in a cross-tabulated table of $I \times J$ cells. Let $N_{i+}$ (for $i=\{1,2, \ldots I\}$ ) denote the marginal population count for the $i$ th row, and let $N_{+j}$ (for $j=\{1,2, \ldots J\})$ denote the marginal population count for the $j$ th column of the crosstabulated table. Assume that $N_{i+}$ and $N_{+j}$ are known. Raking ratio uses iterative steps to obtain the calibrated weights such that the final weighted marginal counts from the sample for all $I$ rows and $J$ columns match their corresponding marginal population counts. This procedure can be easily extended to more than two auxiliary variables (Kalton 1983).

\subsubsection{Raking Ratio for the QNHS}

The CSO uses poststratification to calculate the pre-Q3-2006 and the current QNHS weights. However, poststratification cannot be implemented in two scenarios: first when the poststrata are empty and second when the population counts of the poststrata are unknown or unreliable.

The first scenario can happen, but is most likely not a problem for the QNHS due to their large quarterly sample sizes of approximately 45,000 to 60,000 individuals. In our simulation study, we estimate that empty poststrata occur about one per cent of the time.

The second scenario in which poststratification is not recommended is when the population counts of the poststrata are unknown or not reliable. This was and still is potentially an issue in Ireland, where estimates of population counts are obtained from the latest Census adjusted for migration and vital statistics (Central Statistics Office 2014). The migration statistics come principally from the QNHS. It means that if the QNHS does not capture the migration flow reliably, the migration statistics are not reliable, which subsequently affects the intercensal population estimates. When the Census 2011 figures were released, they revealed that the annual migration statistics between 2006 and 2011 had been underestimated by 75 per cent or 87,000 people (Houses of the Oireachtas 2012). The CSO has since incorporated various administrative data sources to improve its measure of migration statistics, hence, intercensal population estimates. It is, however, not the aim of this article to examine the reliability of Ireland's intercensal population estimates.

When the above scenarios occur, we propose using raking ratio to calculate the QNHS weights. Specifically, raking ratio can be performed using the marginal population counts for 33 margins: 18 age groups (in five-year increments from 0 to $85+$ years), two sex groups, eight NUTS3 regions, and five nationality groups (Irish, UK, OMS, NMS, and Other Nationals). We choose Age, Sex, Region, and Nationality for this weighting method because these four variables are used in the current and the proposed modified QNHS weighting schemes, thus allowing comparability. 
It is noted that raking ratio also depends on reliable marginal population counts, so it faces the same issue discussed in the second scenario. However, potentially unreliable intercensal population estimates have a lesser effect on raking ratio than on poststratification because the former does not require detailed cell counts.

Within the EU, the raking-ratio method is used by Austria and Hungary for their LFS weighting methodologies (Eurostat 2014).

\subsection{Comparison of Weighting Methodologies for the QNHS}

Using the CALMAR 2 macro in SAS, we compute the calibrated weights for each of the following weighting schemes and compare the results. The four schemes are:

1. Pre-Q3-2006 QNHS weighting scheme: complete poststratification by Region (eight NUTS3 regions), Sex, and Age (18 age groups).

2. Current QNHS weighting scheme: simultaneous calibrations to allow poststratification by Region (eight NUTS3 regions), Sex, and Age (18 age groups), as well as poststratification by Sex, Age (under 15, 15+), and Nationality groups (Irish, UK, OMS, NMS, Other).

3. Modified QNHS weighting scheme: simultaneous calibrations to allow poststratification by Region (eight NUTS3 regions), Sex, and Age (18 age groups), as well as poststratification by Sex, Age (under 15, 15-24, 25-49, 50+), and Nationality groups (Irish, UK, OMS, NMS, Other).

4. Raking ratio: calibration on known marginal counts of Region (eight NUTS3 regions), Sex, Age (18 age groups), and Nationality groups (Irish, UK, OMS, NMS, Other).

We measure the performance of each method by calculating the total Mean-Squared Error (MSE) and the total Coefficient of Variation (CV) for all categories of the Principal Economic Status (PES). Initially, we also consider bias as a measure of performance. However, our simulation results show that there is no significant difference in bias across the four weighting schemes. It follows that the weighting scheme with the smallest total MSE and the smallest total CV is considered to be the best method.

It should be pointed out that the QNHS is a household survey, which means that households, not individuals, are the final sampling units. However, the pre-Q3-2006 and the current QNHS weighting schemes involve direct adjustment at individual level instead of household level. To be consistent with the existing QNHS schemes, our two proposed weighting methodologies also perform weight adjustment at individual level. This is a common practice among NSIs conducting the EU-LFS. There are only a few countries, such as Spain, Italy, Hungary, and Lithuania, that adjust the EU-LFS weights at both individual and household levels (Eurostat 2014).

\section{Simulation Procedure and Measures of Performance}

\subsection{Simulation Procedure}

The primary purpose of constructing calibrated weights is to attempt to account for nonresponse bias and other sampling and nonsampling errors. Therefore, we generate samples with nonresponse to evaluate the performance of the four weighting schemes. 
First, 900 samples each of approximately 25,000 observations are drawn from an anonymised subset (ten per cent) of the 2011 Irish Census (Minnesota Population Center 2014). These samples are selected using the same two-stage stratified cluster sample design as the QNHS (Central Statistics Office 2011). In the first stage, Primary Sampling Units (PSUs), each containing approximately 75 households, are selected using Probability Proportional to Size Sampling. In the second stage, 15 households are selected from each PSU using Systematic Sampling. All individuals in the selected households are included in the samples.

Next, we generate nonresponse for each sample. Since the QNHS is a household survey, nonresponse is generated at the household level instead of the individual level. We consider the following six nonresponse (NR) scenarios:

- NR1: We randomly remove $20 \%$ of households from the samples. This is consistent with the general nonresponse level of the QNHS.

- NR2: We generate nonresponse based on NUTS3 regions as reported for the QNHS 2013 (Eurostat 2013). The nonresponse rates for the eight NUTS3 regions are: Border (24.10\%), Midland (16.64\%), West (27.30\%), Dublin (26.54\%), Mid-East (22.70\%), Mid-West (23.22\%), South-East (18.45\%), and South-West (19.20\%).

- NR3: Nonresponse is generated for the two NUTS2 regions reported for the QNHS 2013 (Eurostat 2013). The nonresponse rates for the Border-Mid-West region and for the South-East region are $23.67 \%$ and $22.65 \%$, respectively.

- NR4: Nonresponse rates are generated for different household types. There are four types of households: Cohabiting partners without children, Cohabiting partners with children, Lone parents with children, and Other. Their nonresponse rates are estimated using the QNHS 2011 (Q2) and the Irish Census 2011 samples. The estimated nonresponse rates for these four types of households are $16.37 \%, 15.14 \%$, $23.18 \%$, and $17.53 \%$, respectively.

- NR5: Nonresponse rates depend on urbanicity estimated from the EU-SILC 2011 and the Irish Census 2011 samples. The nonresponse rate for urban areas is $25 \%$, and that for the rural areas is $13 \%$. This is consistent with literature that shows that rural areas are more likely to participate in surveys than urban areas (United Nations 2005; King et al. 2009; Pérez-Duarte et al. 2010).

- NR6: Nonresponse rates vary for Irish households and immigrant households. We categorise a household as an immigrant household if two thirds or more than two thirds of its members are foreign nationals. We then estimate the nonresponse rates for Irish households and immigrant households using the QNHS 2011 (Q2) and the Census 2011. They are $17 \%$ and $39 \%$, respectively.

In each of the six nonresponse scenarios, we obtain 900 final samples. For each of the 900 samples, we compute calibrated weights using the four weighting schemes described in Subsection 2.3. We then obtain the overall PES distribution and that for each of the five nationality groups (Irish, UK, OMS, NMS, and Other). In the following subsection, we describe the two measures of performance used to determine the best weighting scheme for the QNHS. 


\subsection{Measures of Performance}

The PES indicates the status of each individual in the labour force. It has three categories: Employed, Unemployed, and Inactive. Suppose that their corresponding population percentages are $p_{1}, p_{2}$, and $p_{3}$. Let $\hat{p}_{1}, \hat{p}_{2}$, and $\hat{p}_{3}$ be the weighted sample estimates (in percentage) of those employed, unemployed, and inactive, respectively. Let the estimated mean over the Monte Carlo simulations for each PES category be:

$$
\overline{\hat{p}}_{i}=\frac{1}{900} \sum_{k=1}^{900} \hat{p}_{i k} \quad \text { for } \quad i=1,2,3
$$

and the estimated sampling variance be:

$$
\hat{V}\left(\hat{p}_{i}\right)=\frac{1}{899} \sum_{k=1}^{900}\left(\hat{p}_{i}-\overline{\hat{p}}_{i}\right)^{2} \quad \text { for } \quad i=1,2,3
$$

In our study, we use the MSE and the CV as measures of performance. The MSE measures the accuracy of an estimator and is equal to the average squared distance between each sample estimate and the corresponding true population percentage. On the other hand, the CV measures the relative variability of an estimate and is equal to the ratio of the standard error of the estimate and the estimate itself. We estimate the MSE and the CV using the following formulae, with index $i$ indicating the category of PES and $k$ indicating the simulation index.

1. Estimated Mean-Squared Error (MSE)

$$
\begin{aligned}
& \operatorname{MS} E\left(\hat{p}_{i}\right)=\frac{1}{900} \sum_{k=1}^{900}\left(\hat{p}_{i k}-p_{i}\right)^{2} \\
& \operatorname{MSE}(\operatorname{PES})=\sum_{i=1}^{3} \operatorname{MSE}\left(\hat{p}_{i}\right)=\sum_{i=1}^{3}\left[\frac{1}{900} \sum_{k=1}^{900}\left(\hat{p}_{i k}-p_{i}\right)^{2}\right]
\end{aligned}
$$

2. Estimated Coefficient of Variation (CV)

$$
\begin{gathered}
\widehat{\operatorname{CV}}\left(\hat{p}_{i}\right)=\frac{\sqrt{\hat{V}\left(\hat{p}_{i}\right)}}{\overline{\hat{p}}_{i}} \times 100 \% \\
\widehat{\mathrm{CV}}(\mathrm{PES})=\sum_{i=1}^{3} \widehat{\mathrm{CV}}\left(\hat{p}_{i}\right)=\sum_{i=1}^{3}\left[\frac{\sqrt{\hat{V}\left(\hat{p}_{i}\right)}}{\overline{\hat{p}}_{i}}\right] \times 100 \%
\end{gathered}
$$

We consider the best weighting scheme to be the one with the smallest MŜE (PES) (2) and the smallest $\widehat{\mathrm{CV}}$ (PES) (4).

\subsection{MSE and CV Estimation in NSIs}

In this article, we use Monte Carlo simulations to estimate the MSE and the CV, which are functions of the sampling variance. In reality, NSIs around Europe estimate the sampling 
variance not only based on Monte Carlo simulation, but also based on analytic or replication methods.

Variance estimation in a complex sample survey is a challenging task. It depends on the type of sampling design, the type of estimator, the type of nonresponse corrections, and the form of statistics (Eurostat 2002). With the QNHS, it is almost impossible to use exact analytic methods to calculate the sampling variance. This is due to its complex two-stage stratified cluster sample design and its complex weighting scheme. Moreover, our interest in the estimation of the PES distribution for subpopulations (i.e five nationality groups) makes the exact calculation of the sampling variance and hence the MSE and the CV even more unfeasible.

Within the EU, some common variance estimation methods employed by countries for their LFS are the Taylor linearisation, jackknife, bootstrap, balanced repeated replication, and random-groups method. Apart from the Taylor linearisation method, these are replication methods which require intensive computer power. Of these, the jackknife method for variance estimation is recommended by Eurostat's Task Force to all countries except Luxembourg (Eurostat 2002). Currently, the Irish CSO also uses the jackknife method for the QNHS (Central Statistics Office 2015b). If our proposed weighting schemes were to be adopted for the QNHS, we would suggest using the jackknife method to estimate the sampling variance and hence the MSE and the CV.

\section{Results}

As mentioned previously, we use the MSE and the CV as measures of performance in this article. The weighting method with the smallest MŜE (PES) (2) and the smallest $\widehat{C V}$ (PES) (4) is considered the best weighting scheme for the QNHS. We will start this section by discussing the MSE, followed by the CV results.

The MSE is made up of two components, bias and sampling variance, and there is usually a trade-off between these components. In official statistics, interest often lies on obtaining point estimates of the population and subpopulations, so having a small bias is desirable. However, our simulation indicates that there is no significant difference in bias across the four methods, neither for the whole population nor any nationality group (results not shown). It is the difference in the sampling variance that contributes to the difference in the MSE across the four weighting schemes. The MSE results are presented in Table 1 to Table 6.

Table 1. MŜSE (PES) for the whole population.

\begin{tabular}{lcccc}
\hline Scenario & Pre-Q3-2006 & $\begin{array}{c}\text { Current QNHS } \\
\text { weights }\end{array}$ & $\begin{array}{c}\text { Modified QNHS } \\
\text { weights }\end{array}$ & $\begin{array}{c}\text { Raking } \\
\text { ratio }\end{array}$ \\
\hline NR1 & 0.30 & 0.30 & 0.30 & 0.30 \\
NR2 & 0.31 & 0.31 & 0.31 & 0.31 \\
NR3 & 0.31 & 0.31 & 0.31 & 0.31 \\
NR4 & 0.33 & 0.32 & 0.32 & 0.33 \\
NR5 & 0.31 & 0.31 & 0.31 & 0.31 \\
NR6 & 0.30 & 0.30 & 0.30 & 0.29 \\
\hline
\end{tabular}

(Apply to all tables) Within each row, the figure(s) shaded in gray is (are) the smallest. It indicates the best weighting scheme in each nonresponse scenario. 
Table 2. M $\hat{S} E(P E S)$ for the Irish nationals.

\begin{tabular}{lcccc}
\hline Scenario & Pre-Q3-2006 & $\begin{array}{c}\text { Current QNHS } \\
\text { weights }\end{array}$ & $\begin{array}{c}\text { Modified QNHS } \\
\text { weights }\end{array}$ & $\begin{array}{c}\text { Raking } \\
\text { ratio }\end{array}$ \\
\hline NR1 & 0.36 & 0.36 & 0.35 & 0.36 \\
NR2 & 0.38 & 0.38 & 0.37 & 0.38 \\
NR3 & 0.37 & 0.37 & 0.37 & 0.37 \\
NR4 & 0.43 & 0.41 & 0.41 & 0.40 \\
NR5 & 0.38 & 0.37 & 0.35 & 0.38 \\
NR6 & 0.49 & 0.36 & 0.34 & 0.36 \\
\hline
\end{tabular}

Table 3. M $\hat{S} E(P E S)$ for the UK nationals.

\begin{tabular}{lcccc}
\hline Scenario & Pre-Q3-2006 & $\begin{array}{c}\text { Current QNHS } \\
\text { weights }\end{array}$ & $\begin{array}{c}\text { Modified QNHS } \\
\text { weights }\end{array}$ & $\begin{array}{c}\text { Raking } \\
\text { ratio }\end{array}$ \\
\hline NR1 & 10.97 & 10.91 & 10.01 & 10.79 \\
NR2 & 11.77 & 11.69 & 10.43 & 11.63 \\
NR3 & 11.95 & 12.00 & 10.97 & 11.76 \\
NR4 & 11.70 & 11.66 & 10.62 & 11.59 \\
NR5 & 11.24 & 11.23 & 10.12 & 11.01 \\
NR6 & 14.20 & 13.25 & 11.51 & 13.41 \\
\hline
\end{tabular}

Table 4. M $\hat{S} E(P E S)$ for the OMS nationals.

\begin{tabular}{lcccc}
\hline Scenario & Pre-Q3-2006 & $\begin{array}{c}\text { Current QNHS } \\
\text { weights }\end{array}$ & $\begin{array}{c}\text { Modified QNHS } \\
\text { weights }\end{array}$ & $\begin{array}{c}\text { Raking } \\
\text { ratio }\end{array}$ \\
\hline NR1 & 23.50 & 22.89 & 18.70 & 23.32 \\
NR2 & 24.11 & 23.59 & 19.21 & 23.96 \\
NR3 & 23.61 & 23.14 & 18.94 & 23.33 \\
NR4 & 24.61 & 23.90 & 20.18 & 24.47 \\
NR5 & 24.63 & 24.21 & 19.07 & 24.59 \\
NR6 & 27.79 & 27.38 & 22.35 & 27.88 \\
\hline
\end{tabular}

Table 5. M $\hat{S} E(P E S)$ for the NMS nationals.

\begin{tabular}{lcccc}
\hline Scenario & Pre-Q3-2006 & $\begin{array}{c}\text { Current QNHS } \\
\text { weights }\end{array}$ & $\begin{array}{c}\text { Modified QNHS } \\
\text { weights }\end{array}$ & $\begin{array}{c}\text { Raking } \\
\text { ratio }\end{array}$ \\
\hline NR1 & 6.46 & 6.42 & 6.28 & 6.41 \\
NR2 & 6.85 & 6.77 & 6.62 & 6.78 \\
NR3 & 7.19 & 7.12 & 6.94 & 7.15 \\
NR4 & 6.76 & 6.70 & 6.61 & 6.70 \\
NR5 & 7.20 & 7.13 & 6.95 & 7.16 \\
NR6 & 8.78 & 8.61 & 8.48 & 8.65 \\
\hline
\end{tabular}

There are a number of things to note in Tables 1-6. First of all, the proposed modified QNHS weighting scheme produces the smallest MŜE(PES) in 34 out of 36 scenarios presented (six nonresponse scenarios for six groups - the whole population and five nationality groups). In the remaining two scenarios (NR6 for the whole population and 
Table 6. M $\hat{S} E(P E S)$ for other nationals.

\begin{tabular}{lcccr}
\hline Scenario & Pre-Q3-2006 & $\begin{array}{c}\text { Current QNHS } \\
\text { weights }\end{array}$ & $\begin{array}{c}\text { Modified QNHS } \\
\text { weights }\end{array}$ & $\begin{array}{c}\text { Raking } \\
\text { ratio }\end{array}$ \\
\hline NR1 & 8.31 & 8.21 & 7.15 & 8.24 \\
NR2 & 8.76 & 8.64 & 7.39 & 8.72 \\
NR3 & 8.55 & 8.41 & 7.11 & 8.47 \\
NR4 & 8.66 & 8.59 & 7.32 & 8.60 \\
NR5 & 8.68 & 8.56 & 7.34 & 8.60 \\
NR6 & 10.52 & 10.24 & 8.90 & 10.18 \\
\hline
\end{tabular}

NR4 for the Irish nationals), the difference between the MŜE(PES) produced by the modified QNHS weighting scheme and that of the best method in that case is not material. This result is very encouraging because by making a small change to the current QNHS weighting scheme, the modified QNHS scheme repeatedly gives the most accurate estimates.

When we examine Tables 1-6 closely, we do not perceive a material difference in the MŜE(PES) among the four weighting schemes for the whole population in Table 1. In Table 2, even though the modified QNHS method produces the smallest MSE in five out of six nonresponse scenarios, the difference among the MSE figures across the four weighting mechanisms is quite small. This is not surprising since the Irish nationals make up the majority of the population, and thus their behaviour should mimic that of the population. On the other hand, the modified QNHS weighting method consistently produces a large reduction in the MSE for the four immigrant groups - UK, OMS, NMS, and Other Nationals.

Additionally, Tables 1-6 show that the current QNHS weighting method does indeed improve the accuracy of the pre-Q3-2006 scheme. This is expected because the current QNHS weighting method takes the nationality of the respondents into account, while the pre-Q3-2006 scheme does not (Nguyen and Murphy 2015). For the same reason, the raking-ratio method also performs better than the pre-Q3-2006 weighting scheme, since the former also calibrates samples on nationality. When compared with the performance of the current QNHS weighting scheme, the raking-ratio method performs relatively similarly.

A similar pattern is observed with the CV results. The $\widehat{C V}(\mathrm{PES})$ for the whole population and the five nationality groups can be seen in Tables 7-12. The tables show that the modified QNHS weighting scheme produces the smallest $\widehat{\mathrm{CV}}$ (PES) across the board except for the NR6 scenario of the whole population. Overall, the CV findings agree with the MSE results that the modified QNHS weighting scheme is the best out of the four considered weighting mechanisms.

\section{Discussion and Conclusions}

Our simulation results have shown that the modified QNHS weighting scheme gives the best results out of the four weighting methodologies, as demonstrated by its consistently smallest MSE and CV. We also notice that the current QNHS scheme performs better than the pre-Q3-2006 one. However, as the pre-Q3-2006, the current, and the modified QNHS 
Table 7. $\widehat{C V}(P E S)$ for the whole population (\%).

\begin{tabular}{lcccc}
\hline Scenario & Pre-Q3-2006 & $\begin{array}{c}\text { Current QNHS } \\
\text { weights }\end{array}$ & $\begin{array}{c}\text { Modified QNHS } \\
\text { weights }\end{array}$ & $\begin{array}{c}\text { Raking } \\
\text { ratio }\end{array}$ \\
\hline NR1 & 3.76 & 3.77 & 3.75 & 3.76 \\
NR2 & 3.81 & 3.81 & 3.80 & 3.80 \\
NR3 & 3.88 & 3.88 & 3.87 & 3.88 \\
NR4 & 3.73 & 3.73 & 3.72 & 3.73 \\
NR5 & 3.70 & 3.70 & 3.70 & 3.71 \\
NR6 & 3.67 & 3.70 & 3.69 & 3.71 \\
\hline
\end{tabular}

weighting schemes all use the poststratification technique, they cannot be implemented when samples contain empty poststrata or when the population counts for poststrata are unknown or unreliable. When these scenarios occur, we suggest using the raking-ratio method as an alternative weighting scheme. As we discussed in Section 4, the raking-ratio method performs better than the pre-Q3-2006 weighting scheme and similarly to the current one.

While we consider the best weighting method to be the one with the smallest MŜE (PES) (2) and the smallest $\widehat{C V}$ (PES) (4), we also provide the estimated MSE (1) and the estimated CV (3) for each of the three categories of the PES (i.e Employed, Unemployed, and Inactive) in the Appendix A (Tables A.1-A.12). Interestingly, while the modified QNHS weighting scheme outperforms other methods in most scenarios, the raking-ratio method performs better or just as well as the modified QNHS scheme for the Unemployed category of the four immigrant groups (Tables A.5-A.12).

Table 8. $\widehat{C V}(P E S)$ for the Irish nationals (\%).

\begin{tabular}{lcccc}
\hline Scenario & Pre-Q3-2006 & $\begin{array}{c}\text { Current QNHS } \\
\text { weights }\end{array}$ & $\begin{array}{c}\text { Modified QNHS } \\
\text { weights }\end{array}$ & $\begin{array}{c}\text { Raking } \\
\text { ratio }\end{array}$ \\
\hline NR1 & 4.22 & 4.22 & 4.20 & 4.20 \\
NR2 & 4.27 & 4.28 & 4.24 & 4.26 \\
NR3 & 4.30 & 4.30 & 4.26 & 4.29 \\
NR4 & 4.20 & 4.20 & 4.18 & 4.21 \\
NR5 & 4.17 & 4.15 & 4.11 & 4.17 \\
NR6 & 4.12 & 4.11 & 4.07 & 4.12 \\
\hline
\end{tabular}

Table 9. $\widehat{C V}(P E S)$ for the UK nationals (\%).

\begin{tabular}{lcccc}
\hline Scenario & Pre-Q3-2006 & $\begin{array}{c}\text { Current QNHS } \\
\text { weights }\end{array}$ & $\begin{array}{c}\text { Modified QNHS } \\
\text { weights }\end{array}$ & $\begin{array}{c}\text { Raking } \\
\text { ratio }\end{array}$ \\
\hline NR1 & 20.68 & 20.64 & 20.11 & 20.56 \\
NR2 & 21.37 & 21.34 & 20.63 & 21.28 \\
NR3 & 21.55 & 21.56 & 21.00 & 21.42 \\
NR4 & 21.24 & 21.16 & 20.63 & 21.15 \\
NR5 & 20.95 & 20.94 & 20.32 & 20.76 \\
NR6 & 22.13 & 21.95 & 21.26 & 21.98 \\
\hline
\end{tabular}


Table 10. $\widehat{C V}(P E S)$ for the OMS nationals (\%).

\begin{tabular}{lcccc}
\hline Scenario & Pre-Q3-2006 & $\begin{array}{c}\text { Current QNHS } \\
\text { weights }\end{array}$ & $\begin{array}{c}\text { Modified QNHS } \\
\text { weights }\end{array}$ & $\begin{array}{c}\text { Raking } \\
\text { ratio }\end{array}$ \\
\hline NR1 & 37.28 & 36.95 & 35.10 & 37.16 \\
NR2 & 37.99 & 37.78 & 35.89 & 37.93 \\
NR3 & 37.45 & 37.19 & 35.41 & 37.33 \\
NR4 & 37.92 & 37.55 & 36.07 & 37.79 \\
NR5 & 38.11 & 37.83 & 35.74 & 37.96 \\
NR6 & 40.70 & 40.51 & 38.63 & 40.67 \\
\hline
\end{tabular}

While the simulation has shown strong performances and encouraging results, it should be noted that the information on the PSU to which each person or household belongs is not available to us. Therefore, in simulating the 900 QNHS samples (Subsection 3.1), we have to generate artificial PSUs. Because of the artificial PSUs, the clustering effect in our samples is not the same as the real clustering effect.

In reality, it is well known that immigrants usually cluster together in some geographical areas (Robinson 2006; O'Boyle 2009). This means that the proportion of immigrants in some real PSUs would be higher than that in our artificial PSUs. This is because in this study we randomly allocate households among the artificial PSUs, so each artificial PSU would contain approximately the same amount of immigrants.

To understand the effect of artificial PSUs on the robustness of our proposed weighting methods in the estimation of the immigrant population, we have simulated another set of artificial PSUs under an extreme scenario. Instead of being randomly allocated to PSUs as done previously, households are now allocated to either "immigrant" PSUs or Irish PSUs based on their status. A household is classified as an "immigrant" household if two thirds or more than two thirds of their members are foreign nationals. Otherwise, it is classified as an Irish household. All "immigrant" households are randomly allocated to "immigrant" PSUs with each PSU containing approximately 75 households. Similarly, all Irish households are assigned to Irish PSUs, each of 75 households as well. This set-up represents the extreme scenario in which all PSUs are homogeneous with regards to nationality (Irish or non-Irish). When every household in the Census sample is allocated to one PSU, another 900 samples are drawn with the same procedure as described in Subsection 3.1. Of the six nonresponse scenarios considered previously, we pick the sixth nonresponse scenario (NR6) to demonstrate the results, because it is directly linked to

Table 11. $\widehat{C V}(P E S)$ for the NMS nationals (\%).

\begin{tabular}{lcccc}
\hline Scenario & Pre-Q3-2006 & $\begin{array}{c}\text { Current QNHS } \\
\text { weights }\end{array}$ & $\begin{array}{c}\text { Modified QNHS } \\
\text { weights }\end{array}$ & $\begin{array}{c}\text { Raking } \\
\text { ratio }\end{array}$ \\
\hline NR1 & 18.42 & 18.31 & 18.14 & 18.32 \\
NR2 & 19.15 & 19.00 & 18.77 & 19.06 \\
NR3 & 19.44 & 19.28 & 19.06 & 19.37 \\
NR4 & 18.96 & 18.86 & 18.61 & 18.86 \\
NR5 & 19.36 & 19.23 & 19.00 & 19.26 \\
NR6 & 21.41 & 21.24 & 20.99 & 21.36 \\
\hline
\end{tabular}


Table 12. $\widehat{C V}(P E S)$ for other nationals $(\%)$.

\begin{tabular}{lcccc}
\hline Scenario & Pre-Q3-2006 & $\begin{array}{c}\text { Current QNHS } \\
\text { weights }\end{array}$ & $\begin{array}{c}\text { Modified QNHS } \\
\text { weights }\end{array}$ & $\begin{array}{c}\text { Raking } \\
\text { ratio }\end{array}$ \\
\hline NR1 & 17.18 & 17.10 & 16.37 & 17.13 \\
NR2 & 17.51 & 17.43 & 16.63 & 17.45 \\
NR3 & 17.40 & 17.28 & 16.40 & 17.31 \\
NR4 & 17.18 & 17.09 & 16.35 & 17.15 \\
NR5 & 17.61 & 17.52 & 16.71 & 17.53 \\
NR6 & 18.74 & 18.59 & 17.78 & 18.58 \\
\hline
\end{tabular}

immigrants' nonresponse propensity. The MŜE(PES) and the $\widehat{C V}(\mathrm{PES})$ for the NR6 scenario under this new "extreme" PSUs allocation can be seen in Table 13 and Table 14. The estimated MSE and CV for each category of PES in this case are provided in the Appendix B (Tables B.1-B.2).

From Tables 13-14, we see that our modified QNHS weighting scheme also performs the best out of the four weighting methods for all five nationality groups (Irish, UK, OMS, NMS, and Other Nationals) in terms of both MSE and CV. With regards to the distribution of PES for the whole population, all four weighting methods perform equally well on the MSE criterion, but the pre-Q3-2006 weighting scheme produces the smallest CV. However, the difference between the estimated CV under the pre-Q3-2006 scheme and the modified one is minor. The results show the robustness of our proposed modified QNHS weighting scheme to the clustering effect of immigrants.

In conclusion, our study has demonstrated that the proposed modified QNHS weighing scheme is the best weighting method for obtaining the labour-force estimates of the main foreign-national groups while not affecting the estimates on the population and the Irish nationals. Considering the fact that foreign nationals make up a significant portion of Ireland's population and the growing interest in understanding their characteristics, we recommend using our proposed modified QNHS weighting scheme in place of the current scheme for more reliable estimates on Ireland's labour force. In the event that poststratification is not possible as previously discussed, we recommend using the rakingratio method, whose performance is similar to that of the current QNHS scheme, as an alternative weighting scheme.

Although our data are entirely Irish, this study highlights potential issues that other countries may face when using the EU-LFS for immigration research. In recent years,

Table 13. MŜSE (PES) for NR6 with “extreme” PSUs.

\begin{tabular}{lcccr}
\hline Nationality group & Pre-Q3-2006 & $\begin{array}{c}\text { Current QNHS } \\
\text { weights }\end{array}$ & $\begin{array}{c}\text { Modified QNHS } \\
\text { weights }\end{array}$ & $\begin{array}{c}\text { Raking } \\
\text { ratio }\end{array}$ \\
\hline Population & 0.28 & 0.28 & 0.28 & 0.28 \\
Irish & 0.50 & 0.32 & 0.30 & 0.31 \\
UK & 14.98 & 13.97 & 11.92 & 14.21 \\
OMS & 27.83 & 27.55 & 22.15 & 27.80 \\
NMS & 8.94 & 9.05 & 8.79 & 9.03 \\
Other nationals & 10.91 & 10.78 & 9.23 & 10.70 \\
\hline
\end{tabular}


Table 14. $\widehat{C V}(P E S)$ for NR6 with "extreme" PSUs (\%).

\begin{tabular}{lcccr}
\hline Nationality group & Pre-Q3-2006 & $\begin{array}{c}\text { Current QNHS } \\
\text { weights }\end{array}$ & $\begin{array}{c}\text { Modified QNHS } \\
\text { weights }\end{array}$ & $\begin{array}{c}\text { Raking } \\
\text { ratio }\end{array}$ \\
\hline Population & 3.71 & 3.74 & 3.74 & 3.74 \\
Irish & 4.14 & 4.05 & 4.00 & 4.03 \\
UK & 22.66 & 22.49 & 21.74 & 22.53 \\
OMS & 40.82 & 40.74 & 38.49 & 40.77 \\
NMS & 21.42 & 21.48 & 21.02 & 21.43 \\
Other nationals & 19.02 & 18.92 & 17.92 & 18.92 \\
\hline
\end{tabular}

migration has become a global phenomenon with Europe at its centre. A number of European countries have seen an influx of immigrants from other European and nonEuropean states. This is causing a shift in their population demographics that is similar to Ireland's following EU enlargement. As such, there is growing interest in understanding the characteristics of immigrants and their labour-market participation. With its high frequency, large sample sizes, and a certain level of harmonisation among EU countries, the LFS is a popular data source for immigration research. Even though the traditional objective of the EU-LFS is to produce official statistics on the labour force for the whole population, we believe that it is important for the EU-LFS to also produce reliable statistics for the immigrant population.

Other than for Ireland, we have not examined in detail the effectiveness of the EU-LFS weighting schemes for immigration research in other countries. However, an overview of the individual weighting schemes used in the EU-LFS raises some concerns to us. For example, countries with a large number of immigrants such as the UK and Italy, each with a foreign national population of approximately five million (Eurostat 2015), do not have Nationality included in their EU-LFS weighting schemes (Eurostat 2014). Other smaller countries such as Cyprus and Latvia, which rank second and third respectively among the $28 \mathrm{EU}$ countries for the highest proportion of non-nationals in the population (Eurostat 2015), also do not use Nationality as a calibration variable (Eurostat 2014). Our study demonstrates that by making changes to the current LFS weighting schemes, we can achieve more reliable labour-force statistics not only for the whole population, but also for the immigrant one. Therefore, we recommend that other NSIs revisit their EU-LFS weighting schemes for immigration research. 


\section{A. Appendix}

\section{A.1. Whole Population}

Table A.1. MSE for the whole population.

\begin{tabular}{llll}
\hline Scenario & Pre-Q3-2006 Current QNHS weights $\quad$ Modified QNHS weights
\end{tabular}

State 1:

Employed

NR1

NR2

NR3

NR4

NR5

NR6

$\begin{array}{ll}0.13 & 0.13 \\ 0.14 & 0.14 \\ 0.14 & 0.14 \\ 0.15 & 0.15 \\ 0.14 & 0.14 \\ 0.13 & 0.13\end{array}$

0.13
0.14
0.14
0.15
0.14
0.13

State 2:

Unemployed

NR1

NR2

NR3

NR4

NR5

NR6

\begin{tabular}{|c|c|}
\hline 0.07 & 0.07 \\
\hline 0.07 & 0.07 \\
\hline 0.07 & 0.07 \\
\hline 0.09 & 0.08 \\
\hline 0.07 & 0.07 \\
\hline 0.07 & 0.07 \\
\hline
\end{tabular}

0.07
0.07
0.07
0.08
0.07
0.07

State 3:

Inactive

NR1

NR2

NR3

NR4

NR5

NR6

0.10
0.10
0.10
0.09
0.10
0.10

0.10
0.10
0.10
0.09
0.10

0.10
0.10
0.10
0.09
0.10

0.10

0.10

0.10

0.09

0.10

0.10

0.10

0.09

(Apply to all tables) Within each row, the figure(s) shaded in gray is (are) the smallest. It indicates the best weighting scheme in each nonresponse scenario.

Table A.2. CV for the whole population (\%).

\begin{tabular}{lcccc}
\hline Scenario & Pre-Q3-2006 & Current QNHS weights & Modified QNHS weights & \\
\hline State 1: & & & & \\
Employed & & & 0.73 & 0.73 \\
NR1 & 0.73 & 0.73 & 0.75 & 0.75 \\
NR2 & 0.75 & 0.75 & 0.72 & 0.74 \\
NR3 & 0.74 & 0.74 & 0.72 & 0.72 \\
NR4 & 0.72 & 0.72 & 0.72 & 0.72 \\
NR5 & 0.72 & 0.72 & 0.72
\end{tabular}

State 2:

\section{Unemployed}

NR1

NR2

NR3

NR4

NR5

NR6

\section{State 3:}

Inactive

NR1

NR2

NR3

NR4

NR5

NR6

2.21
2.21
2.31
2.20
2.16
2.13

2.20
2.20
2.30
2.19
2.16
2.15

0.82
0.82

0.82
0.85
0.83
0.81
0.82
0.82

0.82
0.85
0.83
0.81
0.82
0.81

0.82
0.85
0.83
0.81
0.82
0.82




\section{A.2. Irish Nationals}

Table A.3. MSE for the Irish nationals.

\begin{tabular}{lcccc}
\hline Scenario & Pre-Q3-2006 & Current QNHS weights & Modified QNHS weights & Raking ratio \\
\hline State 1: & & & & \\
Employed & & & & 0.15 \\
NR1 & 0.16 & 0.16 & 0.16 & 0.17 \\
NR2 & 0.17 & 0.17 & 0.16 & 0.16 \\
NR3 & 0.16 & 0.16 & 0.19 & 0.18 \\
NR4 & 0.20 & 0.18 & 0.16 & 0.17 \\
NR5 & 0.17 & 0.17 & 0.15 & 0.16 \\
NR6 & 0.20 & 0.16 & & \\
\hline
\end{tabular}

State 2:

Unemployed

NR1

NR2

NR3

NR4

NR5

NR6

0.08
0.08
0.08
0.10
0.07
0.08

0.08
0.08
0.08
0.10
0.07
0.07

0.08
0.08
0.08
0.10
0.07
0.07

State 3:

Inactive

NR1

NR2

NR3

0.12
0.13
0.13

0.12
0.13
0.13

NR4

0.13

0.13

NR5

0.14

0.13

NR6

0.21

0.13

Table A.4. CV for the Irish nationals (\%).

\begin{tabular}{lcccc}
\hline Scenario & Pre-Q3-2006 & Current QNHS weights & Modified QNHS weights & Raking ratio \\
\hline State 1: & & & & \\
Employed & & & & 0.79 \\
NR1 & 0.80 & 0.80 & 0.81 & 0.83 \\
NR2 & 0.83 & 0.83 & 0.80 & 0.81 \\
NR3 & 0.82 & 0.82 & 0.79 & 0.80 \\
NR4 & 0.80 & 0.80 & 0.79 & 0.81 \\
NR5 & 0.81 & 0.81 & 0.78 & 0.80 \\
NR6 & 0.80 & 0.80 & &
\end{tabular}

State 2:

Unemployed

NR1

NR2

NR3

NR4

NR5

$$
2.53
$$

2.57

2.51

2.45

2.43

\begin{tabular}{|l|}
\hline 2.53 \\
2.53 \\
2.57 \\
2.51 \\
2.44 \\
2.42
\end{tabular}

\begin{tabular}{|l|}
2.53 \\
2.53 \\
2.57 \\
2.51 \\
2.44 \\
2.42
\end{tabular}

State 3:

Inactive

\begin{tabular}{lllll} 
NR1 & 0.89 & 0.89 & 0.88 & 0.88 \\
NR2 & 0.92 & 0.92 & 0.90 & 0.91 \\
NR3 & 0.91 & 0.91 & 0.89 & 0.90 \\
NR4 & 0.89 & 0.89 & 0.88 & 0.89 \\
NR5 & 0.91 & 0.90 & 0.88 & 0.90 \\
NR6 & 0.89 & 0.89 & 0.87 & 0.89 \\
\hline
\end{tabular}




\section{A.3. UK Nationals}

Table A.5. MSE for the UK nationals.

\begin{tabular}{llll}
\hline Scenario & Pre-Q3-2006 & Current QNHS weights & Modified QNHS weights
\end{tabular}

State 1:

Employed

NR1

4.52

4.93

4.93

NR3

4.86

4.58

NR5

6.09

$$
\begin{aligned}
& 4.49 \\
& 4.87 \\
& 4.96 \\
& 4.82 \\
& 4.56 \\
& 5.62
\end{aligned}
$$

NR6

4.13
4.32
4.52
4.38
4.07
4.77

State 2:

Unemployed

NR1

NR2

NR3

NR4

NR5

2.12
2.25
2.30
2.27
2.20
2.31

2.13

2.27

2.29

2.27

2.21

NR6

2.30

\begin{tabular}{l|l}
2.12 & 2.11 \\
2.26 & 2.25 \\
2.29 & 2.28 \\
2.27 & 2.27 \\
2.20 & 2.18 \\
2.29 & 2.29 \\
\hline
\end{tabular}

State 3:

Inactive

\begin{tabular}{llllll} 
NR1 & 4.33 & 4.29 & 3.76 & 4.23 \\
NR2 & 4.59 & 4.55 & 3.85 & 4.52 \\
NR3 & 4.72 & 4.75 & 4.16 & 4.61 \\
NR4 & 4.57 & 4.57 & 3.97 & 4.51 \\
NR5 & 4.46 & 4.46 & 3.85 & 4.35 \\
NR6 & 5.80 & 5.33 & 4.45 & 5.43 \\
\hline
\end{tabular}

Table A.6. CV for the UK nationals (\%).

\begin{tabular}{lll}
\hline Scenario & Pre-Q3-2006 Current QNHS weights $\quad$ Modified QNHS weights
\end{tabular}

\section{State 1:}

Employed

\begin{tabular}{lll} 
NR1 & 4.49 & 4.48 \\
NR2 & 4.69 & 4.66 \\
NR3 & 4.69 & 4.71 \\
NR4 & 4.64 & 4.62 \\
NR5 & 4.52 & 4.51 \\
NR6 & 4.78 & 4.74 \\
\hline
\end{tabular}

\section{State 2:}

Unemployed

$\begin{array}{lllll}\text { NR1 } & 10.91 & 10.92 & 10.89 & 10.87 \\ \text { NR2 } & 11.24 & 11.28 & 11.25 & 11.23 \\ \text { NR3 } & 11.36 & 11.34 & 11.33 & 11.32 \\ \text { NR4 } & 11.21 & 11.18 & 11.20 & 11.18 \\ \text { NR5 } & 11.11 & 11.13 & 11.10 & 11.05 \\ \text { NR6 } & 11.41 & 11.35 & 11.31 & 11.33\end{array}$

\section{State 3:}

\section{Inactive}

NR1

NR2

NR3

NR4

NR5

NR6

$\begin{array}{ll}5.28 & 5.24 \\ 5.44 & 5.39 \\ 5.50 & 5.51 \\ 5.39 & 5.36 \\ 5.32 & 5.30 \\ 5.94 & 5.86\end{array}$

$\begin{array}{ll}4.29 & 4.46 \\ 4.39 & 4.66 \\ 4.49 & 4.66 \\ 4.41 & 4.62 \\ 4.26 & 4.47 \\ 4.55 & 4.76\end{array}$

4.46

4.66

4.47

4.76 


\section{A.4. OMS Nationals}

Table A.7. MSE for the OMS nationals.

Scenario Pre-Q3-2006 Current QNHS weights $\quad$ Modified QNHS weights Raking ratio

State 1:

Employed

NR1

$\begin{array}{ll}10.43 & 10.15\end{array}$

NR2

10.77

10.53

NR3

10.37

10.87

10.18

NR4

NR5

10.91

10.56

NR6

12.54

10.74

12.40

8.16
8.51
8.21
8.78
8.27
10.01

10.33

10.67

10.23

10.78

10.93

12.61

State 2:

Unemployed

NR1

3.14
3.33
3.20
3.23
3.30
3.84

3.14

3.16

3.33

3.37

3.25

3.21

NR3

3.21

3.27

3.34

3.87

3.95

NR6

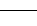

State 3:

Inactive

NR1

NR2

NR3

$\begin{array}{rr}9.93 & 9.60 \\ 10.01 & 9.73 \\ 10.04 & 9.75 \\ 10.51 & 10.13 \\ 10.42 & 10.17 \\ 11.41 & 11.11\end{array}$

NR4

NR5

11.41

10.17
11.11

Table A.8. CV for the OMS nationals (\%).

\begin{tabular}{|c|c|c|c|c|}
\hline Scenario & Pre-Q3-2006 & Current QNHS weights & Modified QNHS weights & Raking ratio \\
\hline \multirow{2}{*}{\multicolumn{5}{|c|}{$\begin{array}{l}\text { State 1: } \\
\text { Employed }\end{array}$}} \\
\hline & & & & \\
\hline NR1 & 5.06 & 4.99 & 4.47 & 5.03 \\
\hline NR2 & 5.14 & 5.09 & 4.57 & 5.12 \\
\hline NR3 & 5.05 & 5.00 & 4.49 & 5.01 \\
\hline NR4 & 5.17 & 5.09 & 4.64 & 5.14 \\
\hline NR5 & 5.18 & 5.13 & 4.50 & 5.18 \\
\hline NR6 & 5.57 & 5.52 & 4.96 & 5.57 \\
\hline \multicolumn{5}{|c|}{$\begin{array}{l}\text { State 2: } \\
\text { Unemployed }\end{array}$} \\
\hline NR1 & 20.81 & 20.73 & 20.80 & 20.75 \\
\hline NR2 & 21.41 & 21.41 & 21.53 & 21.39 \\
\hline NR3 & 20.93 & 20.88 & 21.04 & 20.92 \\
\hline NR4 & 21.04 & 20.94 & 21.19 & 20.96 \\
\hline NR5 & 21.36 & 21.26 & 21.43 & 21.23 \\
\hline NR6 & 22.99 & 22.95 & 23.23 & 22.95 \\
\hline \multicolumn{5}{|l|}{$\begin{array}{l}\text { State 3: } \\
\text { Inactive }\end{array}$} \\
\hline NR1 & 11.41 & 11.23 & 9.83 & 11.38 \\
\hline NR2 & 11.44 & 11.28 & 9.79 & 11.42 \\
\hline NR3 & 11.47 & 11.31 & 9.88 & 11.39 \\
\hline NR4 & 11.71 & 11.51 & 10.24 & 11.70 \\
\hline NR5 & 11.57 & 11.44 & 9.81 & 11.55 \\
\hline NR6 & 12.14 & 12.04 & 10.44 & 12.15 \\
\hline
\end{tabular}




\section{A.5. NMS Nationals}

Table A.9. MSE for the NMS nationals.

\begin{tabular}{lllll}
\hline Scenario & Pre-Q3-2006 & Current QNHS weights & Modified QNHS weights & Raking ratio
\end{tabular}

\section{State 1:}

Employed

\begin{tabular}{lllll} 
NR1 & 3.01 & 3.01 & 2.92 & 2.99 \\
NR2 & 3.12 & 3.09 & 3.01 & 3.09 \\
NR3 & 3.31 & 3.29 & 3.18 & 3.30 \\
NR4 & 3.07 & 3.05 & 3.01 & 3.04 \\
NR5 & 3.37 & 3.34 & 3.24 & 3.36 \\
NR6 & 4.05 & 3.97 & 3.91 & 3.97 \\
\hline
\end{tabular}

State 2:

Unemployed

\begin{tabular}{lllll} 
NR1 & 2.08 & 2.07 & 2.06 & 2.07 \\
NR2 & 2.20 & 2.20 & 2.19 & 2.18 \\
NR3 & 2.40 & 2.40 & 2.38 & 2.38 \\
NR4 & 2.23 & 2.23 & 2.22 & 2.22 \\
NR5 & 2.32 & 2.32 & 2.31 & 2.31 \\
NR6 & 2.90 & 2.89 & 2.89 & 2.87 \\
\hline
\end{tabular}

State 3:

\section{Inactive}

NR1

NR2

NR3

NR4

NR5

$\begin{array}{ll}1.37 & 1.34 \\ 1.53 & 1.48 \\ 1.48 & 1.43 \\ 1.46 & 1.42 \\ 1.51 & 1.47 \\ 1.83 & 1.75\end{array}$

NR6

Table A.10. CV for the NMS nationals (\%).

\begin{tabular}{lcccc}
\hline Scenario & Pre-Q3-2006 & Current QNHS weights & Modified QNHS weights & Raking ratio \\
\hline State 1: & & & & \\
Employed & & & & 2.58 \\
NR1 & 2.59 & 2.59 & 2.56 & 2.62 \\
NR2 & 2.63 & 2.62 & 2.59 & 2.71 \\
NR3 & 2.71 & 2.70 & 2.67 & 2.62 \\
NR4 & 2.64 & 2.63 & 2.61 & 2.70 \\
NR5 & 2.70 & 2.70 & 2.67 & 3.00 \\
NR6 & 3.02 & 3.00 & 2.98 & \\
\hline
\end{tabular}

State 2:

Unemployed

\begin{tabular}{lll} 
NR1 & 7.33 & 7.32 \\
NR2 & 7.54 & 7.55 \\
NR3 & 7.88 & 7.88 \\
NR4 & 7.59 & 7.59 \\
NR5 & 7.75 & 7.75 \\
NR6 & 8.63 & 8.61 \\
\hline State 3: & & \\
Inactive & & \\
NR1 & 8.50 & 8.40 \\
NR2 & 8.98 & 8.83 \\
NR3 & 8.85 & 8.70 \\
NR4 & 8.73 & 8.64 \\
NR5 & 8.91 & 8.78 \\
NR6 & 9.76 & 9.63
\end{tabular}

\begin{tabular}{lll}
7.32 & 7.29 & 7.31 \\
7.55 & 7.52 & 7.51 \\
7.88 & 7.85 & 7.84 \\
7.59 & 7.58 & 7.57 \\
7.75 & 7.73 & 7.73 \\
8.61 & 8.61 & 8.58 \\
\hline
\end{tabular}

State 3:

Inactive

\begin{tabular}{lllll} 
NR1 & 8.50 & 8.40 & 8.29 & 8.43 \\
NR2 & 8.98 & 8.83 & 8.66 & 8.93 \\
NR3 & 8.85 & 8.70 & 8.54 & 8.82 \\
NR4 & 8.73 & 8.64 & 8.42 & 8.67 \\
NR5 & 8.91 & 8.78 & 8.60 & 8.83 \\
NR6 & 9.76 & 9.63 & 9.40 & 9.78 \\
\hline
\end{tabular}




\section{A.6. Other Nationals}

Table A.11. MSE for the other nationals.

\begin{tabular}{llll}
\hline Scenario & Pre-Q3-2006 Current QNHS weights & Modified QNHS weights
\end{tabular}

State 1:

Employed

NR1 3.25

$\begin{array}{lll}\text { NR2 } & 3.61 & 3.55\end{array}$

$\begin{array}{lll}\text { NR3 } & 3.37 & 3.30\end{array}$

$\begin{array}{lll}\text { NR4 } & 3.51 & 3.47\end{array}$

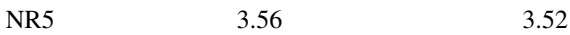

$\begin{array}{lll}\text { NR6 } & 4.16 & 3.07\end{array}$

$\begin{array}{lll}3.21 & 2.74 & 3.22 \\ 3.55 & 2.94 & 3.59 \\ 3.30 & 2.69 & 3.35 \\ 3.47 & 2.93 & 3.49 \\ 3.52 & 2.89 & 3.53 \\ 4.07 & 3.55 & 4.08\end{array}$

State 2:

Unemployed

NR1

NR2

1.85

$1.86-1.86$

NR3

NR4

NR5

NR6

$1.86-1.88$

$\begin{array}{ll}1.87 & 1.88\end{array}$

$\begin{array}{ll}1.86 & 1.88\end{array}$

\begin{tabular}{l|l}
1.87 & 1.87
\end{tabular}

2.27

2.26

1.86
1.90
1.89
1.87
1.91
2.24

State 3:

\section{Inactive}

\begin{tabular}{lllll} 
NR1 & 3.21 & 3.14 & 2.55 & 3.17 \\
NR2 & 3.29 & 3.21 & 2.55 & 3.28 \\
NR3 & 3.31 & 3.23 & 2.53 & 3.27 \\
NR4 & 3.29 & 3.24 & 2.51 & 3.26 \\
NR5 & 3.25 & 3.17 & 2.54 & 3.20 \\
NR6 & 4.09 & 3.91 & 3.11 & 3.88 \\
\hline
\end{tabular}

Table A.12. CV for the other nationals (\%).

\begin{tabular}{llll}
\hline Scenario & Pre-Q3-2006 Current QNHS weights & Modified QNHS weights
\end{tabular}

\section{State 1:}

Employed

NR1

NR2

NR3

NR4

NR5

NR6

$\begin{array}{ll}3.84 & 3.81 \\ 4.05 & 4.01 \\ 3.91 & 3.87 \\ 3.99 & 3.96 \\ 4.03 & 4.00 \\ 4.36 & 4.30\end{array}$

3.53
3.66
3.49
3.65
3.62
4.00

State 2:

Unemployed

NR1

NR2

8.56

8.61

8.63

8.39

8.77

9.05

NR5

NR6

State 3:

Inactive

\begin{tabular}{lll} 
NR1 & 4.78 & 4.72 \\
NR2 & 4.85 & 4.79 \\
NR3 & 4.86 & 4.79 \\
NR4 & 4.80 & 4.74 \\
NR5 & 4.81 & 4.76 \\
NR6 & 5.33 & 5.26 \\
\hline
\end{tabular}

\subsection{5}

8.63

8.62

8.39

8.76

9.03

8.58
8.70
8.66
8.47
8.83
9.07




\section{B. Appendix}

Table B.1. MSE for the NR6 scenario with "extreme" PSUs.

Nationality group Pre-Q3-2006 Current QNHS weights Modified QNHS weights Raking ratio

\section{State 1:}

Employed

Population

Irish

UK

OMS

NMS

Other nationals

\begin{tabular}{rr}
0.12 & 0.12 \\
0.20 & 0.14 \\
6.37 & 5.96 \\
12.58 & 12.47 \\
4.25 & 4.32 \\
4.30 & 4.31 \\
\hline
\end{tabular}

0.12
0.13
5.02
9.92
4.21
3.74

0.12

0.13

6.03

12.62

4.32

4.28

State 2:

Unemployed

Population

Irish

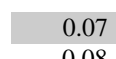

UK

OMS

NMS

Other nationals

\subsection{8}

2.55

3.91

2.79

2.26

0.07
0.08
2.54
3.94
2.82
2.22

0.07
0.07
2.51
3.93
2.84
2.20

State 3:

\section{Inactive}

Population

Irish

UK

OMS

NMS

Other nationals

0.09
0.22
6.05
11.34
1.91
4.35

0.09
0.11
5.47
11.13
1.91
4.24

0.09

0.10

4.39

8.31

1.74

3.28
0.09

0.11

5.69

11.28

1.91

4.23

Table B.2. CV for the NR6 scenario with "extreme” PSUs.

\begin{tabular}{lllll}
\hline Nationality group & Pre-Q3-2006 Current QNHS weights & Modified QNHS weights & Raking ratio
\end{tabular}

\section{State 1:}

\section{Employed}

Population

Irish

UK

OMS

NMS

Other nationals

$\begin{array}{ll}0.69 & 0.70 \\ 0.76 & 0.74 \\ 5.06 & 4.99 \\ 5.56 & 5.53 \\ 3.11 & 3.12 \\ 4.43 & 4.43\end{array}$

0.70
0.73
4.74
4.94
3.08
4.12

0.70

0.73

5.02

5.57

3.12

4.41

\section{State 2:}

Unemployed

Population

Irish

UK

OMS

NMS

Other nationals

\begin{tabular}{|c|c|}
\hline 2.23 & 2.25 \\
\hline 2.51 & 2.48 \\
\hline 11.66 & 11.66 \\
\hline 23.13 & 23.11 \\
\hline 8.37 & 8.37 \\
\hline 9.09 & 9.00 \\
\hline
\end{tabular}

2.25
2.47
11.65
23.12
8.40
8.97

State 3:

Inactive

Population

Irish

UK

OMS

12.13

12.10

NMS

9.94

9.99

Other nationals

5.50

5.49

0.79
0.80
5.36
10.43
9.54
4.84
5.50 


\section{References}

Barrett, A., A. Bergin, and E. Kelly. 2011. "Estimating the Impact of Immigration on Wages in Ireland." The Economic and Social Review 42: 1-26.

Barrett, A. and D. Duffy. 2008. "Are Ireland's Immigrants Integrating into Its Labor Market?” International Migration Review 42: 597-619. Doi: http://dx.doi.org/10.1111/ j.1747-7379.2008.00139.x.

Central Statistics Office. 2011. "Quarterly National Household Survey Quarter 2 2011." Available at: http://www.cso.ie/en/media/csoie/releasespublications/documents/ labourmarket/2011/qnhs_q22011.pdf (accessed 21 December 2015).

Central Statistics Office. 2014. "Population and Migration Estimates.” Available at: http:// www.cso.ie/en/surveysandmethodology/population/populationandmigrationestimates/ (accessed 14 January 2016).

Central Statistics Office. 2015a. "Estimated Population classified by Sex and Nationality, 2009-2015 [Table 9]." Available at: http://www.cso.ie/en/releasesandpublications/er/ pme/populationandmigrationestimatesapril2015/ (accessed 19 January 2016).

Central Statistics Office. 2015b. "Standard Report on Methods and Quality for QNHS." Cork. Available at: http://www.cso.ie/en/qnhs/qnhsmethodology/ (accessed 19 January 2016). Deming, W.E. and F.F. Stephan. 1940. "On a Least Squares Adjustment of a Sampled Frequency Table When the Expected Marginal Totals are Known." The Annals of Mathematical Statistics 11: 427-444. Doi:http://dx.doi.org/10.1214/aoms/ 1177731829.

Deville, J.C. and C.-E. Särndal. 1992. "Calibration Estimation in Survey Sampling." Journal of the American Statistical Association 87: 376-382.

Deville, J.C., C.-E. Särndal, and O. Sautory. 1993. "Generalized Raking Procedures in Survey Sampling.” Journal of the American Statistical Association 88: 1013-1020.

Djerf, K. 1997. "Effects of Post-Stratification on the Estimates of the Finnish Labour Force Survey." Journal of Official Statistics 13: 29-39.

Djerf, K. and P. Väisänen. 1993. "Effects of Post-Stratication on the Estimates of the Finnish Labour Force Survey." International Statistical Institute 49th Session, Contributed Papers, Book 1. Florence: ISI, 375-376.

Eurostat. 2002. "Monograph of Offcial Statistics - Variance Estimation Methods in the European Union." Luxembourg: Eurostat. Available at: http://ec.europa.eu/eurostat/ ramon/statmanuals/files/KS-CR-02-001-EN.pdf (accessed 21 January 2016).

Eurostat. 2013. "Employment and Unemployment (Labour Force Survey) [Ireland]." Available at: http://ec.europa.eu/eurostat/cache/metadata/EN/employ_esqrs_ie.htm (accessed May 2015).

Eurostat. 2014. "Labour Force Survey in the EU, Candidate and EFTA countries - Main characteristics of national surveys, 2013." Eurostat Methodologies and Working Paper. Luxembourg: Eurostat.

Eurostat. 2015. "Share of Non-Nationals in the Resident Population, 1 January 2014 [Table 4]." Available at: http://ec.europa.eu/eurostatstatisticsexplained/index.php/ Migration_and_migrant_population_statistics (accessed 3 February 2016).

Holt, D. and T.M.F. Smith. 1979. "Post-Stratification." Journal of the Royal Statistical Society Series A 142: 33-46. 
Hörngren, J. 1992. "The Use of Registers as Auxiliary Information in the Swedish Labour Force Survey." In Proceedings of the Workshop on Uses of Auxiliary Information in Surveys, 5-7 October 1992, Örebro. Statistics Sweden and the University of Örebro.

Houses of the Oireachtas. 2012. Parliamentary Debates on Migration Data, 18 September 2012 (Minister of State at the Department of the Taoiseach, Deputy Paul Kehoe). Available at: http://oireachtasdebates.oireachtas.ie/debates\%20authoring/debates webpack.nsf/takes/dail2012091800054?opendocument\#WRD01250 (accessed 22 January 2016).

Jagers, P. 1986. "Post-Stratification Against Bias in Sampling." International Statistical Review 54: 159-167.

Kalton, G. 1983. "Compensating for Missing Survey Data.” Ann Arbor, MI: Survey Research Center, Institute for Social Research, the University of Michigan.

King, S.L., B. Chopova, J. Edgar, J.M. Gonzalez, D. McGrath, and L. Tan. 2009. "Assessing Nonresponse Bias in the Consumer Expenditure Interview Survey." In Proceedings of the Section on Survey Research Methods: Joint Statistical Meetings of the American Statistical Association, 6 August 2009, Washington, DC. Available at: http://www.bls.gov/osmr/pdf/st090220.pdf (accessed June 2015).

Kingston, G., P.J. O'Connell, and E. Kelly. 2013. "Ethnicity and Nationality in the Irish Labour Market: Evidence from the QNHS Equality Module 2010.” Dublin: Equality Authority/ESRI.

Martí, M. and C. Ródenas. 2012. "Measuring International Migration through Sample Surveys: Some Lessons from the Spanish Case.” Population 67: 235-463.

Minnesota Population Center. 2014. "Integrated Public Use Microdata Series, International: Version 6.3 [Machine-readable database]." Minneapolis: University of Minnesota.

Nguyen, N.D. and P. Murphy. 2015. "To Weight or Not To Weight - A Statistical Analysis of How Weights Affect the Reliability of the Quarterly National Household Survey for Immigration Research in Ireland." Journal of Economic and Social Reviews 46: $567-603$.

O'Boyle, N. and B. Fanning. 2009. "Immigration, Integration and Risks of Social Exclusion: The Social Policy Case for Disaggregated Data in the Republic of Ireland." Irish Geography 42: 145-164. Doi: http://dx.doi.org/10.1080/00750770903112795 (accessed 01 February 2016).

O’Connell, P.J. and F. McGinnity. 2008. "Immigrants at Work: Nationality and Ethnicity in the Irish Labour Market.” Dublin: Equality Authority/ESRI.

Pérez-Duarte, S., C. Sánchez Muñoz, and V.-M. Törmälehto. 2010. "Reweighting to Reduce Unit Nonresponse Bias in Household Wealth Surveys: A Cross-Country Comparative Perspective Illustrated by a Case Study." In Proceedings of the Conference on European Quality in Statistics, May 4-6, 2010, Helsinki. Available at: http://www. ecb.europa.eu/home/pdf/research/hfcn/WealthSurveys.pdf (acccessed June 2015).

Robinson, D. and K. Reeve. 2006. Neighbourhood Experiences of New Immigration: Reflections from the Evidence Base. London: Joseph Rowntree Foundation.

Särndal, C.-E. 2007. "The Calibration Approach in Survey Theory and Practice." Survey Methodology 33: 99-119. 
Särndal, C.-E. and S. Lundström. 2005. Estimation in Surveys with Nonresponse. New York: Wiley.

Sautory, O. 2003. "CALMAR 2: A New Version of the CALMAR Calibration Adjustment Program.” In Proceedings of Statistics Canada's Symposium 2003 Challenges in Survey Taking for the Next Decade. Available at: http://www.statcan.gc.ca/pub/11-522-x/ 2003001/session13/7713-eng.pdf (accessed June 2016).

Thomsen, I. 1973. "A Note on the Efficiency of Weighting Subclass Means to Reduce the Effects of Non-Response when Analyzing Survey Data." Statistisk Tidskrift 11: $278-285$.

Thomsen, I. 1978. "A Second Note on the Efficiency of Weighting Subclass Means to Reduce the Effects of Non-Response when Analyzing Survey Data." Statistisk Tidskrift 16: 278-285.

Thomsen, I. and A.M.K. Holmøy. 1998. "Data from Surveys and Administrative Record Systems. The Norwegian Experience." International Statistical Review 66: 201-221.

United Nations. 2005. "Household Sample Surveys in Developing and Transition Countries.” Available at: http://unstats.un.org/unsd/hhsurveys/pdf/Household_surveys.pdf (accessed June 2015).

Villund, O. 2010. "Effect of Non-Response Bias on Labour Market Statistics for Immigrants." In Proceedings of the 5th Workshop on Labour Force Survey Methodology, 15-16 May 2010, Paris. Available at: http://www.insee.fr/en/inseestatistique-publique/connaitre/colloques/wlfsm/documents/wlfsm-villund-paper.pdf (accessed June 2015).

Zhang, L.-C. 2000. "Post-Stratification and Calibration - A Synthesis." The American Statistician 54: 178.

Received August 2015

Revised February 2016

Accepted April 2016 